hacer" transmitido (know-how) y la asistencia aportada por el franquiciante sean aprovechadas por la competencia, no constituyen practicas restrictivas de la competencia en el seno del art. 85, parr. 1ro."

- las clausulas que organizan el control indispensable para preservar la identidad y reputacion de la cadena que esta simbolizada por la enseña, no consituyen de ningun modo restricciones a la competencia en el sentido del art. 85 parr 1 ro.

? "las clausulas que representen una division y reparto de los mercados entre franquiciante y franquiciado, o entre franquiciados, constituyen restricciones a la competencia en la interpretacion de la misma norma;"

Este enfoque, a nuestro juicio correcto, parte de la premisa de que la red no es por su sola existencia violatoria de derecho protectorio de la competencia en el mercado. Sobre esta base, hay que examinar claùsulas especìficas que como, las que de acuerdo de precios, constituyen restricciones a la libre competencia.

Una de las estipulaciones del contrato de franquicia que ha provocado litigiosidad en cuanto a su ilicitud a la luz de la normativa "antitrust" es aquella que permite al franquiciador seleccionar a los franquiciados, ya sea en base a determinados criterios previamente establecidos o a mero acuerdo del franquiciador e incluso de los franquiciados existentes en el área geográfica. Este tipo de cláusulas han sido analizadas por la jurisprudencia "antitrust" norteamericana como un supuesto de negativa de venta o negativa a contratar, considerando por tanto legitimas. Sólo en aquellos casos en que la negativa es parte de un boycot, que tenga como finalidad excluir una firma del mercado, estarán prohibidas $^{59}$.

Otro de los tipos de estipulaciones que plantean dudas acerca de su licitud en el contrato de franquicia son las que determinan un reparto geográfico de mercados entre los distintos franquiciados y aun entre éstos y el franquiciador con el consiguiente reparto de la clientela. La jurisprudencia norteamericana ha considerado la legitimidad de este tipo de cláusulas si persigue la protecciòn de los los signos distintivos del franquiciador que el franquiciado usa en su establecimiento, porque exigir al franquiciado vender solamente los productos designados por el franquiciador o prohibirle vender productos no compatibles, dada la necesidad de preservar el interés legítimo de éste al mantenimiento del crédito de una marca.

\title{
Direitos Fundamentais no Estado Constitucional Democrático
}

Para a relação entre direitos do homem, direitos fundamentais, democracia e jurisdição constitucional

$$
\text { Robent EAlexy*, EKiel-OHemanha }
$$

Tradutor: Dr. Luís Afonso Heck - Prof. na UFRGS e ULBRA

\section{RESUMO}

artigo ocuba-se primeiro com os três problemas dos direitos do homm Depois

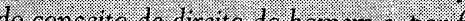
, por $f \mathrm{~m}$, anal Cos nocracia e a jurisdição constitucional.

\begin{tabular}{|l}
\hline \multicolumn{1}{|c|}{ SUMÁRIO } \\
I. Os três problemas dos direitos do ho- \\
mem. \\
1. Os problemas epistemológicos. \\
2. Os problemas substanciais. \\
3. Os problemas institucionais. \\
II. O conceito de direito do homem. \\
1.Direitos universais. \\
2.Direitos morais. \\
3.Direitos preferenciais. \\
4.Direitos fundamentais. \\
5. Direitos abstratos. \\
III. Direitos fundamentais, democracia e \\
jurisdição constitucional. \\
1. Quatro extremos. \\
2. Três modelos. \\
3. Representação politica eargumenta- \\
tiva.
\end{tabular}

Revista da Faculdade de Direito da UFRGS, v. 16, 1999
Passaram-se, hoje quase no dia, exatamente 50 anos desde que a Assembléia Geral das Naçōes Unidas votou a Declara ção Universal dos Direitos do Homem em 10 de dezembro de 1948. Nisto, não se tratou de alguma das numerosas resoluções das Nações Unidas. Norberto Bobbio qualificou acertadamente a Declaração Universal dos Direitos do Homem como a "até agora maior prova histórica para o 'consensus omnium gentium' com respeito a um sistema de valores determinado". ${ }^{1}$ Que se tratava de um consenso sobre valores fundamentais de significado eminente estava claro ao 48 Estados então representados na Assembléia Geral. O preâmbulo exprime isso impressionantemente pelo fato de qualificar os direitos do homem "como o ideal comum a ser alcançado por todos os povos e nações". Com isso, estão claramente

Palestra inaugural da comemoração dos cem anos da Faculdade de Direito da UFRGS, proferida no dia 9 de dezem bro de 1998 no Salăo Nobre da Faculdade de Direito da UFRGS.

1. Norberto Bobbio, Das Zeitalter der Menchenrechte, Berlin 1998, S. 9. 
duas qualidades fundamentais dos direitos do homem desde o início diante dos olhos: os direitos do homem são um ideal universal.

\section{Os três problemas dos direitos do homem}

Uma apresentação tão pretenciosa como um ideal universal deve suscitar, forçosamente, de modo direto, numerosas questões e a literatura, desmesurada para os direitos do homem, mostra que isso de nenhuma maneira é somente uma suposição. Os problemas que estão unidos com os direitos do homem deixam-se dividir em três grupos.

\section{Os problemas epistemológicos}

Ao primeiro grupo pertencem os problemas epistemológicos. Neles, trata-se da questão se e como os direitos do homem podem ser conhecidos ou fundamentados. Podem os direitos do homem, em verdade, ser conhecidos objetivamente ou o consenso de 10 de dezembro de 1948 foi somente uma concordância contingente, condicionada pelos horrores de ambas as guerras, de opiniões subjetivas, o que iria significar que aquele consenso, com a mudança dessas opiniões, perderia todo significado? Este é o lugar da objeção de Alasdair MacIntyres citada com freqüência: "There are no such rights, and belief in them is one with belief in witches and in unicorns:" Com isto, o primeiro problema está diante dos olhos: podem, em verdade, qualquer direitos do homem ser justificados ou fundamentados

racionalmente? Apesar de seu caráter filosófico esse problema tem, de todo, significado prático. Assim que o consenso em questões de direitos do homem vacila, a possibilidade de alegar fundamentos para elas ganha em significado. Enquanto todos acreditam firmemente nos direitos do homem a sua fundamentação é um problema meramente teórico; ele se torna tanto mais prático quanto mais forte cresce a dúvida fundamental.

\section{Os problemas substanciais}

Os problemas do segundo grupo nascem assim que se põe de acordo sobre isto, que direitos do homem devem ser reconhecidos. Surge então a questão, que direitos são direitos do homem. Este é o problema substancial dos direitos do homem. A Declaração Universal dos Direitos do Homem contém nos artigos 1 até 20 os direitos de liberdade e igualdade clássicos como eles, no Virginia Bill of Rights, de 12 de junho de 1776, no primeiro catálogo de direitos fundamentais amplo, são indicados. $\mathrm{O}$ artigo 21 regula a participação na formação da vontade política. Também isso está na tradição liberal e democrática do Virginia Bill of Rights. Mas então começa um novo capítulo. $\mathrm{O}$ artigo 22 promete "segurança social" e "direitos econômicos, sociais e culturais", o artigo 23 normaliza um direito ao trabalho, a "condições de trabalho apropriadas e satisfatórias assim como à proteção contra desemprego", o artigo 24 concede um direito ao "descanso e tempo livre", o artigo 25 dá a cada homem um "direito a um nível de vida que garanta saúde e bem-estar seu e de sua família, inclusive a alimentação, vestuário, moradia, a assistência médica e as prestações necessárias da assistência social", o artigo 26 estabelece o direito à educação e o artigo 27 coroa tudo isso com o direito "de participar livremente na vida cultural da comunidade, de alegrar se com as artes e de ter parte no progresso científico e do seu benefício". Com isso, os direitos do homem sociais - muitas vezes, também, chamados direitos do homem de segunda geração - encontraram aceitação plenamente na Declaração Universal dos Direitos do Homem. Estão eles, todavia também fundamentados em medida igual como os direitos liberais da primeira geração? Tem eles a mesma força? Sobre isso existe discussão. Muito mais discussão exis te sobre a questão se aos direitos de primeira e segunda deve ser adicionada ainda uma família de direitos de terceira geração. São considerados como tais, sobretudo, direitos de Estados, povos ou grupos ao fomento do desenvolvimento. ${ }^{3}$ Finalmente, existe a possibilidade de pôr em jogo aspectos ecológicos. Poder-se-ia assim, se não se quer embrulhar todo o novo sem classificar, chegar a uma quarta geração ou dimensão. A discussão, ademais, não só trata do que deve ser incluído na lista dos direitos do homem. Ela desencadea-se, sobretudo, em volta da questão de como devem ser ponderados as diferentes gerações ou dimensões. Um exemplo para uma tal discussão é a polêmica durante toda a guerra fria entre o Oeste e o Leste sobre isto, se o primado corresponde aos direitos do homem liberais

ou sociais. As linhas de frente removeramse hoje mas a estrutura lógica da polêmica permaneceu igual.

\section{Os problemas institucionais}

O terceiro problema principal dos direitos do homem é o da sua institucionalização. Também aqui vale a pena a leitura da Declaração Universal dos Direitos do Homem. $\mathrm{O}$ artigo 28 é, à primeira vista, uma prescrição peculiar. Ele diz que todo o homem tem um direito "a uma ordem social e internacional na qual os direitos e liberdades mencionados na presente declaração podem ser realizados". Isso pode ser compreendido como direito à institucionalização. Como mera declaração, um catálogo de direitos do homem permanece sem efeito. Os direitos do homem devem ser transformados em direito positivo para que seu cumprimento esteja garantido. O preâmbulo manifesta isto claramente quando ele diz que "é essencial proteger os direitos do homem pelo domínio do direito". Existem dois planos principais da institucionalização, o nacional e o internacional. Ambos podem, dentro de si, ser divididos, novamente, muitas vezes. Assim, existe em um sistema federal nacional dois planos. Ademais, o plano nacional e o internacional estão hoje estreitamente entrelaçados um com o outro, o que se mostra, por exemplo, no fato de que o Pacto Internacional sobre Direitos Civis e Políticos, de 19 de dezembro de 1966, foi transformado em direito intra-estatal por numerosos Estados.

3. Comparar K. J. Partsch, Das Recht auf "internationale Solidarität" - ein neues "Menchenrecht der dritten Generation"? in Europäische Grundrechte-Zeitschrift 1980, S. 511 f. E. Riedel, Menchenrechte der dritten Generation, in: Europäische GrundrechteZeitschritt 1989, S. 12 ff. 
É impossível atravessar todos os três círculos de problemas, aqui, também, so mente uma parte vastamente. Eu irei con centrar-me, por conseguinte, no problema institucional e, com isso, limitar-me ao quadro nacional. O significado da proteção ao direitos do homem internacional não pode, sem dúvida, ser sobrestimado. Sem a concretização dos direitos do homem por meio dos Estados particulares, o ideal do qual fala o preâmbulo, todavia, jamais pode tornar-se realidade. Também nisso vale o princípio da subsidiariedade.

A concentração sobre a institucionalização em Estados particulares é, sem dúvida, não mais do que a possibilidade ou facilidade de um primeiro passo. É de todo indiferente onde se começa nos direitos do homem, sempre se chega a todos os problemas. Assim, a solução da questão institucional está unida estreitamente com a da substancial. Quem reconhece catálogos amplos com direitos de todas as gerações será muito aplaudido em certas discussões. Para isso, ele precisa aceitar problemas na institucionalização, porque vale a tese de que os direitos do homem são tão mais difíceis de concretizar quanto mais eles prometem. Mesmo entre o plano epistemológico e o institucional existem conexões mais estreitas. Quanto melhor direitos do homem são fundamentados, tanto mais legítima é a sua concretização internacional por força. Os direitos do homem formam, assim, com todos os seus problemas, um sistema.

Para chegar a este sistema, do lado institucional, deve ser efetuado, primeiro, uma determinação do conceito de direito do homem. Nisso, a necessidade de sua transformação em direitos fundamentais jurídico-positivamente vigentes irá resultar como que por si mesmo. Em um segundo passo eu quero, então, mostrar quais problemas nascem disto para o princípio democrático. No fim, eu espero poder mostrar uma solução que impeça uma autodestruição da idéia dos direitos do homem por meio de uma contradição interna.

\section{O conceito de direito do homem}

Os direitos do homem distinguemse de outros direitos ${ }^{4}$ pela combinação de cinco marcas. Eles são direitos (1) universais, (2) morais, (3) fundamentais, (4) preferenciais e (5) abstratos.

\section{Direitos universais}

Da universalidade já se tratava na caracterização dos direitos do homem como ideal universal. Agora, este conceito deve ser determinado mais pormenorizadamente. Um primeiro aspecto da universalidade é a universalidade dos titulares e destinatários. Aqui, deve ser lançado somente um olhar sobre os titulares. ${ }^{5}$

A universalidade da titularidade consiste nisto, que direitos do homem são direitos que cabem a todos os homens. A

4. Para o conceito do direito (subjetivo), comparar R. Alexy, Theorie der Grundrechte, 3. Aufl., Frankfurt a.M. 1996, S. $171 \mathrm{ff}$.

5. Para a universalidade dos destinatários, comparar R. Alexy, Die Institutionalisierung der Menschenrechte im demokratischen Verfassungsstaat, in: Stefan Gesepath/Georg Lohmann (Hg.), Philosophie der Menschenrechte, Frankfurt a.M. 1998, S. 248. determinação do círculo dos titulares causa vários problemas, dos quais dois devem aqui interessar. $\mathrm{O}$ primeiro resulta do emprego do conceito de homem. A delimitação mais clara se obtém quando se define este conceito biologicamente. Ao contrário, é objetado que isso é uma especificidade que se aproxima do racismo. ${ }^{6}$ Essa objeção não vê, todavia, que no emprego do conceito biológico do homem para a delimitação do círculo de titulares se trata somente do conceito de direito do homem, não, porém, de sua fundamentação. Se os fundamentos melhores falassem a favor disto, de conceder determinados direitos, por exemplo, à vida, a animais em igual proporção como aos homens, então o direito à vida, como direito do homem, estaria caduco e deveria ser criado novamente, por exemplo, como "direito da criatura" com círculo de titulares alargado.

O segundo problema nasce disto, que então, quando se considera o conceito biológico do homem, somente homens como indivíduos podem ser titulares de direitos do homem. Contra isso poder-se-ia objetar que existem, todavia, bons fundamentos para isto, de atribuir também a grupos, comunidades e Estados determinados direitos, por exemplo, direitos à existência, identidade ou desenvolvimento. Novamente deve ser acentuado que aqui não se trata da fundamentação de quaisquer direitos, senão somente de uma formação de conceito adequada. Grupos, comunidades e Estados compõem-se, sem dúvida, de homens mas não são homens. O que concerne

6. Comparar C. S. Nino, The Ethics of Human Rights, Oxford 1991, S. 35

7. BVerfGE 4,7 (15 f). ao conceito de direito do homem, assim, não causa problemas, de um direito do homem do particular falar depois que seu grupo, sua comunidade ou seu Estado é protegido na existência, na identidade ou no desenvolvimento. $O$ titular de tais direitos, que têm a integração do particular em sua comunidade como objeto e fundamento, permanece o homem particular. Trata-se, em tais direitos, de um alargamento dos direitos individuais à existência e desenvolvimento da personalidade na dimensão da comunidade. As coisas, porém, modificam-se quando, como titulares desses direitos, aparecem o grupo, a comunidade ou o Estado. Podem existir bons fundamentos para tais direitos, mas eles deveriam ser qualificados como o que são, ou seja, como "direitos de grupo", "de comunidade" ou "de Estado". Isso tem, sem dúvida, a desvantagem de que, para os de fensores de tais direitos, se perde o som bonito da expressão "direitos do homem". Mas, para isso, nasce clareza. Ademais, permanece possível fundamentar direitos de coletividades como meio para a realização de direitos do homem. Tudo isso aguça a vista para isto, que direitos coletivos não degenerem em direitos de funcionário. Por fim, trata-se disto, de, com todo "o estar relacionado à comunidade e o estar vinculado à comunidade", ? ater-se à proteção do particular como intenção original dos direitos do homem. Isso não exclui cimentar na constituição direitos coletivos - como, por exemplo, também a proteção de bens coletivos - Todos os direitos do homem merecem, como ainda deverá ser mostrado,

Revista da Faculdade de Direito da UFRGS, v. 16, 1999 
proteção jurídico-constitucional, mas não tudo que merece proteção jurídico-constitucional deve ser um direito do homem. Basta que ele, para falar como Rawls, faça parte do "constitutional essentials". ${ }^{8}$ Com o auxílio deste conceito o uso inflacionário da expressão "direito do homem" pode ser limitado, que não faz bem à matéria dos direitos do homem.

\section{Direitos morais}

A segunda qualidade essencial para os direitos do homem é que eles são direitos morais. $O$ conceito de direito moral é ambíguo. Aqui ele deve ser empregado como conceito contrário para o conceito de direito jurídico-positivo. Direitos jurídicopositivos nascem - como todas as normas do direito positivo - por atos de disposição, por exemplo, por contrato, poder constituinte, lei aprovada ou uma prática judicial ou social e dependem em sua existência novamente como todas as normas do direito positivo - disto, se eles obtêm e mantêm um mínimo de eficácia ou oportunidade de eficácia social. ${ }^{9}$ Direitos morais podem, simultaneamente, ser direitos jurídico-positivos, sua validez, porém, não pressupõe uma positivação. Para a validez ou existência de um direito moral basta que a norma, que está na sua base, valha moralmente. Uma norma vale moralmente quando ela, perante cada um que aceita uma fundamentação racional, pode ser justificada. ${ }^{10}$ Direitos do homem existem, com isso, exatamente então quando eles, no sentido

apresentado, podem ser justificados perante cada um. À universalidade da estrutura dos direitos do homem, que consiste nisto, que eles são, fundamentalmente, direitos de to dos contra todos, cabe, com isso, uma universalidade de validez que é definida por sua fundamentabilidade perante cada um que aceita uma fundamentação racional.

\section{Direitos preferenciais}

Apesar de seu caráter moral, direi tos do homem estão em uma relação íntima com o direito. Se existe um direito moral, portanto, fundamentável perante cada um, por exemplo, à vida, então também deve existir um direito, fundamentável perante cada um, à concretização daquele direito. Se se quer evitar guerra civil entra em questão, como instância de concretização, somente o Estado. $O$ direito moral à vida implica, portanto, um direito moral à proteção por direito positivo estatal. Nesse sentido, existe um direito ao Estado, mais sucintamente, um direito moral ao direito positivo. A Declaração Univer sal dos Direitos do Homem manifesta isto, como já observado, muito bem em seu preâmbulo e no artigo 28 .

O direito do homem ao direito positivo não é um direito do homem ao direito positivo de qualquer conteúdo, senão a um direito positivo que respeita, protege e fomenta os direitos do homem, porque é exatamente $o$ asseguramento dos direitos do homem que fundamenta o direito do homem ao direito positivo. A observação aos

8. Comparar J. Rawls, Political Liberalism, New York 1993, S. 227 ff.

9. Comparar para isso, R. Alexy, Begriff und Geltung des Rechts, 2. Aufl., Freiburg/München 1994, S. $147 \mathrm{f}$.

10. Comparar para isso, R. Alexy, Diskurstheorie und Menchenrechte, in: ders., Recht, Vernunft, Diskurs. Studien zur Rechtsphilosophie Frankfurt a.M. 1995, S. 127 H. direitos do homem é uma condição necessária para a legitimidade do direito positivo. Nisto, que o direito positivo deve respeitar, proteger e fomentar os direitos do homem para ser legítimo, portanto, ser suficiente à sua pretensão à exatidão, manifesta-se a prioridade dos direitos do homem. Direitos do homem estão, com isso, em uma relação necessária com o direito positivo, que está caracterizada pela prioridade dos direitos do homem. Essa prioridade neces. sária é a terceira marca definidora dos direitos do homem.

\section{Direitos fundamentais}

A relação interna, definida pela prioridade necessária, entre direitos do homem como direitos morais e o direito positivo desempenha na questão, quais conteúdos têm direitos do homem, um papel decisivo. Nos objetos dos direitos do homem deve tratar-se de interesses e carências para os quais valem coisas distintas. Deve tratarse, em primeiro lugar, de interesses e carências que, em geral, podem e devem ser protegidos e fomentados por direito. Assim, muitos homens têm uma carência fundamental de amor. Não deve haver poucos aos quais é mais importante ser amado do que participar em demonstrações políticas. Contudo, não existe um direito do homem ao amor, porque amor não se deixa forçar pelo direito. A segunda condição é que o interesse ou a carência seja tão fundamental que a necessidade de seu respeito, sua proteção ou seu fomento se deixe fundamentar pelo direito. A fundamentabilidade fundamenta, assim, a prioridade sobre todos os escalões do sistema jurídico, portanto, também perante o legislador. Um interesse ou uma carência é, nesse sentido, fundamental quando sua violação ou não-satisfação significa ou a morte ou sofrimento grave ou toca no núcleo essencial da autonomia. Daqui são compreendidos não só os direitos de defesa liberais clássicos, senão, por exemplo, também direitos sociais que visam ao asseguramento de um mínimo existencial. Não são direitos do homem, segundo esse critério da fundamentabilidade, pelo contrário, por exemplo, o direito garantido no artigo 7, VIII, da Constituição brasileira, a um 13 ordenado mensal ou a garantia, lá escrita no artigo $230, \S 2^{\circ}$, do livre aproveitamento dos meios de transporte urbanos públicos para os maiores de 65 anos.

\section{Direitos abstratos}

A quinta marca característica para direitos do homem é que neles se trata de direitos abstratos. Isso se mostra mais claramente na necessidade de sua restrição ou limitação que, por direitos de outros e pelo mandamento da conservação e fomento de bens coletivos como, por exemplo, da proteção do meio ambiente, é exigida. Qual restrição é admissível pode, no fundo, ser determinado apenas por ponderação. A aplicação dos direitos do homem em casos concretos pressupõe, com isso, ponderações. Sobre ponderações, porém, pode-se discutir longamente. Se a discussão não deve perdurar eternamente, o que iria pôr em perigo a realização dos direitos do homem, devem ser criadas instâncias que estão autorizadas a decisões de ponderação juridicamente obrigatórias. O Estado é, portanto, necessário não só como instância de concretização mas também como instância de decisão para a realização dos direitos do 
homem. Acresce que a realização de numerosos direitos do homem não é possíve sem organização. Nem a proteção diante de atos de violência de outros cidadãos nem o cuidado pelo mínimo existencial podem ficar a cargo de ação espontânea, se se tratar de uma garantia. Os direitos do homem conduzem, portanto, por três fundamento para a necessidade do Estado e do direito: por causa da necessidade de sua concretização, se for necessário, também com coação, da necessidade de não só dis cutir sobre questões de interpretação e pon deração mas também decidi-las e por causa da necessidade de organizar o cumprimen to de direitos do homem. A passagem dos direitos do homem, como direitos morais para o direito positivo não significa, decer to, sua despedida. O contrário é exato, por que a parte essencial dessa passagem é transformação dos direitos do homem em direitos fundamentais de conteúdo igual. $O$ direitos do homem não perdem, nessa trans formação, em validez moral, ganham, po rém, adicionalmente uma jurídico-positiva. A espada torna-se afiada. Primeiro, com isso, está efetuado definitivamente o passo do império das idéias para o império da his tória.

\section{Direitos fundamentais, democracia e jurisdição constitucional}

Poder-se-ia achar que com a codificação dos direitos do homem por uma constituição, portanto, com sua transformação em direitos fundamentais, o problema de sua institucionalização esteja resolvido. Isso não é, todavia, o caso. Muitos problemas dos direitos do homem agora somente tornam-se visíveis em toda sua dimensão e novos acrescem por seu caráter obrigatório, agora existente.

\section{Quatro extremos}

As fontes das dificuldades que se manifestam com a institucionalização são quatro extremos que caracterizam direitos fundamentais completamente formados. $\mathrm{O}$ primeiro extremo é o escalão hierárquico supremo na ordem escalonada do direito intraestatal. Resulta do mero fato de que direitos fundamentais são direitos com hierarquia constitucional. O escalão hierárquico supremo seria sem interesse se não acrescesse o segundo, a força de concretização suprema. Dela dispõem direitos fundamentais quando eles primeiro vinculam todos os três poderes, portanto, também o legislador e quando essa vinculação é controlada judicialmente, portanto, é justiciável. Se se excetuasse o legislador dessa vinculação ou se se declarasse alguns direitos fundamentais como não-justiciáveis, então desapareceriam, sem dúvida, muitos problemas. $\mathrm{O}$ preço para isso seria, todavia, alto. Ele residiria em uma renúncia a uma institucionalização completa ou autêntica. Uma tal renúncia, porém, seria uma infração contra direitos do homem. Constituições modernas dão aos direitos fundamentais em geral, por conseguinte, a força de concretização suprema e quando elas não o fazem deveriam ou ser interpretadas neste sentido ou, quando isso não fosse possível, modificadas.

Também a união entre escalão hierárquico supremo e força de concretização suprema iriam significar pouco se os direitos fundamentais regulassem questões es- peciais sem importância. Exatamente o contrário é, porém, o caso. Com a garantia da propriedade, da liberdade de profissão e da liberdade de contratar toma-se a decisão para uma economia de mercado. A garan tia da liberdade de opinião, imprensa e da liberdade de radiodifusão e televisiva põe os pilares de um sistema de comunicação social. Outros direitos fundamentais precisam ser apenas mencionados para conhecer seu signficado fundamental, assim, a garantia do casamento e família e a do direito de sucessão, a liberdade de religião e a proteção da vida e integridade corporal.

Convertem-se em um verdadeiro problema os três extremos tratados até agora, o escalão hierárquico supremo, a força de concretização suprema e os objetos sumamente importantes, primeiro pelo enlace com um quarto problema, a medida máxima de necessidade de interpretação. Na maioria das constituições isso já resulta da redação concisa e lapidar de seu catálogo de direitos fundamentais. Mas também lá onde uma redação mais exata dos direitos fundamentais é tentada, as coisas não são muito diferentes. Assim, os direitos de liberdade e igualdade clássicos são regulados no artigo $5^{\circ}$ da Constituição brasileira em 74 números e os direitos sociais no artigo $7^{\circ}$ em 34 números, assim como em muitas outras prescrições do título oitavo sobre a ordem social. Os problemas de interpretação jurídico-fundamentais que aparecem em toda a parte são, por meio dessa regulação relativamente detalhada, abafados em parte ampla mas não eliminados; em alguns casos nascem até novos. Assim, o artigo 5º, IV, declara a manifestação dos pensamentos como livre. Isso quer dizer que todas as manifestações de opinião são permitidas, também tais que violam a honra de outros e tais com conteúdo racista? Isso prestar-se-ia mal ao artigo $5^{\circ}, \mathrm{X}$, que protege a honra, e ao artigo $5^{\circ}$, XLII, que prevê uma pena às práticas racistas. Em contrapartida, nem toda a manifestação de opinião que de alguma maneira ofenda um concidadão ou membro de uma determinada raça pode ser proibida se a liberdade de manifestação de opinião não deve atrofiar. Isso mostra que uma fixação de limite com auxílio de uma ponderação é necessária. A ponderação como parte de um exame de proporcionalidade, porém, é o problema nuclear da dogmática dos direitos fundamentais e a razão principal para a abertura dos catálogos de direitos fundamentais. Em alguns casos, esse problema salta diretamente aos olhos, por exemplo, quando o artigo 5o, XXII, garante a propriedade e então, imediatamente, é adicionado no inciso XXIII que a propriedade deve servir à sua função social. Em outros casos, a necessidade de um exame de proporcionalidade fica clara primeiro no olhar mais de perto, por exemplo, quando o artigo 5, XI, admite a entrada na casa de dia em virtude de ordem judicial. Isso não pode significar que tribunais, por qualquer fundamento, devam admitir uma penetração na casa. A penetração deve ser proporcional. Coisa semelhante vale para os direitos de igualdade. Quando o artigo 5 fixa a fórmula clássica, que todos os homens são iguais diante da lei, para o Brasil, então isso não significa que não deva ser diferenciado. Essa pres. crição não prescreve, por exemplo, que pobres e ricos devam pagar impostos no mesmo nível. Isso mostra que diferencia- 
ções são permitidas se para elas existem fundamentos razoáveis. Discussão especial do mina em vários Estados sobre a fórmula que se encontra no artigo 5ㅇ, I, que homens mulheres têm os mesmos direitos. Isso ex clui discriminação inversa a favor de mulheres, ele a admite ou ela é até exigida? Problemas análogos existem em muitos di reitos fundamentais sociais. Tome-se so mente o direito à saúde, regulado no artigo 196. Ele deve ser garantido por medidas de política social e econômica. Sem pondera ção não pode ser verificado o conteúdo exato desse direito.

Interpretado deve ser em muitos se tores. A força rompante da interpretação constitucional resulta dos três extremo primeiro citados, do escalão hierárquico supremo, da força de concretização supre ma e do conteúdo sumamente importante. Quem tiver êxito, o tribunal, que decide, ao fim e ao cabo, sobre a constitucionalidade e com isso - independente de sua designa ção - desempenha a tarefa de um tribuna constitucional, de convencer de sua con cepção sobre a interpretação dos direitos fundamentais alcançou o que no processo político ordinário é inalcançável: ele tornou sua concepção sobre coisas sociais e políti cas sumamente importantes praticamente partes integrantes da constituição e, com isso, tomou da ordem do dia política. Uma maioria parlamentar simples não pode, en tão, fazer mais nada. Somente o tribunal constitucional mesmo ou a respectiva mai oria qualificada exigida para modificações constitucionais podem, então, ainda modificar a situação. Tudo isso demonstra porque em todos os Estados dotados com catálogo de direitos fundamentais e jurisdi- ção constitucional sobre a interpretação dos direitos fundamentais não só é refletido com calma mas também discutido na arena política. Pode-se falar de uma luta pela interpretação dos direitos fundamentais. Árbitro nessa luta, porém, não é o povo, senão o tribunal constitucional respectivo. Isso é compatível com o princípio democrático, cujo cerne, no artigo $1^{\mathrm{o}}$, parágrafo único, da Constituição brasileira, assim como no artigo 20, alínea 2, frase 1, da Lei Fundamental, é expressado com a fórmula clássica: "Todo o poder estatal origina-se do povo"? Os direitos do homem parecem converter-se em um problema para a democracia quando eles são levados a sério e de um mero ideal tornados em algo real. É exata essa impressão? É o ideal, do qual se trata no preâmbulo da Declaração Universal dos Direitos do Homem, uma quimera que leva à rebentação uma contradição entre direitos fundamentais e democracia?

\section{Três modelos}

Para responder essa questão devem ser diferenciados três modos de visão da relação entre direitos fundamentais e democracia: um ingênuo, um idealista e um realista. Segundo o modo de visão ingênuo, entre direitos fundamentais e democracia já por isso não pode existir conflito, porque tanto direitos fundamentais como democracia são algo bom. Como devem colidir duas coisas boas? A concepção ingênua acha, por isso, que se pode ter ambos juntos ilimitadamente. Essa visão de mundo é muito bonita para ser verdadeira. Seu ponto de partida, que somente existem conflitos entre o bom e o mau, não, porém, no interior do bom, é falso. Quem quer impugnar que prosperidade e pleno emprego, que assentam sobre crescimento econômico, são algo bom em si e quem quer desmentir que a proteção e a conservação do meio ambiente é algo bom? Contudo, existe entre esses bens, de fundamentos bem conhecidos, no nosso mundo caracterizado por finitude e escassez, um conflito. O modo de visão idealista admite isso. Sua reconciliação entre direitos fundamentais e democracia, por conseguinte, - dito exageradamente - também de modo nenhum primeiro tem lugar neste mundo, senão no ideal de uma sociedade politicamente perfeita. Nela, o povo e seus representantes políticos de modo nenhum estão interessados nisto, de violar os direitos fundamentais de algum cidadão por decisões de maioria parlamentares, portanto, leis, ao contrário. A defesa dos direitos fundamentais é um motivo político eficaz para todos. O catálogo de direitos fundamentais tem nesse modelo rousseauniano somente ainda um significado simbólico. Ele formula somente ainda aquilo que todos, alías, acreditam e querem. Como ideal, que pode ser oposto à realidade política e ao qual dever-se-ia acercar, tem esse modelo absolutamente seu valor. Todavia, pode-se saber que esse ideal é inalcançável. Por conseguinte, para aquele que quer institucionalizar os direitos do homem no mundo como ele é, somente o modo de visão realista é exato. Segundo ele, a relação entre direitos fundamentais e democracia é caracterizada por duas compreensões em sentido contrário e, com isso, na realidade, por uma contradição. A primeira soa:

(1) Direitos fundamentais são democráticos,

a segunda:
(2) Direitos fundamentais são ademocráticos.

Direitos fundamentais são democráticos por isso, porque eles, com a garantia dos direitos de liberdade e igualdade, asseguram o desenvolvimento e existência de pessoas que, em geral, são capazes de manter o processo democrático na vida e porque eles, com a garantia da liberdade de opinião, imprensa, radiodifusão, reunião e associação, assim como com o direito eleitoral e com as outras liberdades políticas asseguram as condições funcionais do processo democrático. Ademocráticos são os direitos fundamentais, pelo contrário, porque eles desconfiam do processo democrático. Com a vinculação também do legislador eles subtraem da maioria parlamentarmente legitimada poderes de decisão. Em muitos Estados este jogo deve ser observado: a oposição perde primeiro no processo democrático e ganha, então, diante do tribunal constitucional. Também a Constituição brasileira conhece essa possibilidade ao ela conceder, no artigo 103, VII aos partidos políticos representados no congresso, o direito a uma ação por causa de inconstitucionalidade diante do tribunal constitucional.

Esse caráter duplo dos direitos fundamentais deve ser antipático a defensores de uma doutrina pura. Esses espreitam em ambos os lados do problema. Há tanto adeptos de um processo democrático ilimitado quanto ao conteúdo (em geral, eles são idealistas rousseaunianos dissimulados ou abertos) como céticos democráticos, para os quais existe uma ordem dada das coisas que pelo processo democrático somente é posta em desordem e, por isso, deveria ser prote- 
gida ainda muito mais intensamente por direitos fundamentais e outros princípios constitucionais do que isso hoje, em geral, ocorre. Nem um nem outro pode aqui ser seguido. A questão deve, antes, rezar se a contradição pode ser resolvida pelo fato de ser encontrado um caminho entre essas posições extremas.

\section{Representação política e argumentativa}

A chave para a resolução é a distinção entre a representação política e a argumentativa do cidadão. O princípio fundamental: "Todo o poder estatal origina-se do povo" exige compreender não só o parlamento mas também o tribunal constitucional como representação do povo. A representação ocorre, decerto, de modo diferente. $O$ parlamento representa o cidadão politicamente, o tribunal constitucional argumentativamente. Com isso, deve ser dito que a representação do povo pelo tribunal constitucional tem um caráter mais idealístico do que aquela pelo parlamento. A vida cotidiana do funcionamento parlamentar oculta o perigo que maiorias se imponham desconsideradamente, emoções determinem o acontecimento, dinheiro e relações de poder dominem e simplesmente sejam cometidas faltas graves. Um tribu- nal constitucional que se dirige contra tal não se dirige contra o povo senão, em nome do povo, contra seus representantes políticos. Ele não só faz valer negativamente que o processo político, segundo critérios jurí dico-humanos e jurídico-fundamentais, fracassou mas também exige positivamente que os cidadãos aprovem os argumentos do tribunal se eles aceitarem um discurso jurídico-constitucional racional. A representação argumentativa dá certo quando o tribunal constitucional é aceito como instância de reflexão do processo político. Isso é o caso, quando os argumentos do tribunal encontram um eco na coletividade e nas instituições políticas, conduzem a reflexões e discussões que resultam em convencimentos examinados. Se um processo de refle xão entre coletividade, legislador e tribunal constitucional se estabiliza duradouramente pode ser falado de uma institucionalização que deu certo dos direitos do homem no estado constitucional democrático. Direitos fundamentais e democracia estão então reconciliados. Com isso está assegurado, como resultado, que o ideal, do qual fala a Declaração Universal dos Direitos do Homem, pode ser realizado e não precisa fracassar em uma contradição interna entre direitos fundamentais e democracia.

\section{Reparación limitada del daño en materia de accidentes}

\section{Robento ell. Loper Cabana}

Director del Departamento de Derecho Privado. Professor titular regular de Obligaciones y de Contratos Civiles y Comerciales en la Universidad de Buenos Aires. Professor visitante en las Universidades de Panthéon-Assas (Paris, Francia), de Caxias do Sul (Brasil), Gabriela Mistral

(Santiago de Chile), Mayor de San Marcos (lima) y Católica de Asunción (Paraguay)

\section{Los accidentes}

\section{SUMÁRIO}

I. Los accidentes.

II. La llamada reparación integral.

III. La limitación del resarcimiento en la responsabilidad objetiva.

IV. Excepciones a la limitación.

$V$. La potestad judicial de reducir la indemnización.

VI. La reparación plena y su eventual atenuación

VII. Autotransporte público de pasajeros:

VIII. Prospectiva.

IX. Reformas aconsejables.

$X$. Colofón.
1Diccionario de la Real Academia Es-

pañola, tan ponderado por la doctrina jurídica ${ }^{1}$, registra diez acepciones de la palabra "accidente". Interesan básicamente la segunda y la tercera, que lo caracterizan como un "suceso eventual que altera el orden regular de las cosas", y en un sentido más restringido, del "que involuntariamente resulta daño para las personas o las cosas".

Jurídicamente, un accidente es cualquier acontecimiento productor de un daño, sea imprevisto o eventual o previsible, y cualquiera sea su origen: el hecho del hombre o de la naturaleza.

En el plano económico, un accidente es apenas "un riesgo".

1. CASTAN VÁZQUEZ, José María, "El lenguaje jurídico en España y en la República Argentina", en Temas de Derecho Privado X, Facultad de Derecho y Ciencias Sociales de la Universidad de Buenos Aires - Colegio de Escribanos de la Capital Federal, Buenos Aires, 1998.

2. CALABRESI, Guido, The cost of accidents. A legal and economic analysis, New Haven and London, Yale University Press, 1970 pág. 5.

Revista da Faculdade de Direito da UFRGS, v. 16, 1999 